\title{
EDITORIAL
}

\section{Death Toll From Uncontrolled Blood Pressure in Ethnic Populations: Universal Access and Quality Improvement May Not Be Enough}

\author{
Crystal Wiley Cené, $M D, M P H^{1}$ \\ Lisa A. Cooper, $M D, M P H^{2,3.4}$ \\ 'Division of General Medicine, University of North Carolina at Chapel Hill, Chapel Hill \\ ${ }^{2}$ Division of General Internal Medicine, Department of Medicine, Johns Hopkins University School of Medicine, Baltimore, Maryland \\ ${ }^{3}$ Welch Center for Prevention, Epidemiology, and Clinical Research, Johns Hopkins Medical Institutions, Baltimore, Maryland
}

${ }^{4}$ Departments of Epidemiology and Health Policy and Management, Johns Hopkins Bloomberg School of Public Health, Baltimore, Maryland

Ann Fam Med 2008;6:486-489. DOI: 10.1370/afm.922.

C ardiovascular disease (CVD) is the number 1 cause of death globally. ${ }^{1}$ An estimated 17.5 million from coronary heart disease and 7.6 million from stroke), representing $30 \%$ of all global deaths. ${ }^{2}$ Globally, two-thirds of stroke and one-half of ischemic heart disease are attributable to nonoptimal blood pressure. Worldwide, nonoptimal blood pressure contributes to approximately $12.8 \%$ of all deaths $(7.1$ million) and $4.4 \%$ of all disability-adjusted life years (64.3 million) in the year 2000. These proportions are highest in more developed countries, such as the United States and the United Kingdom. ${ }^{3}$ Racial and ethnic disparities in cardiovascular disease prevalence, treatment, and outcomes are well documented in the United States, and racial and ethnic differences in hypertension are no exception. ${ }^{4-7}$ Cardiovascular disease accounts for $35 \%$ of excess overall mortality in US blacks, largely because of hypertension. ${ }^{8}$ In Europe, ethnic differences in hypertension prevalence and morbidity and mortality from cardiovascular disease have also been described. ${ }^{9,10}$

Conflicts of interest: none reported

\section{CORRESPONDING AUTHOR}

Lisa A. Cooper, MD, MPH

Welch Center for Prevention, Epidemiology, and Clinical Research Johns Hopkins Medical Institutions

2024 East Monument St, Suite 2-500

Baltimore, MD 21287

lisa.cooper@jhmi.edu
Two articles in this issue of the Annals of Family Medicine address ethnic disparities in hypertension care and control, each study examines the disparities problem from a different vantage point. The study by Fiscella and Holt ${ }^{11}$ quantifies the impact of racial differences in hypertension control on cardiovascular and cerebrovascular mortality in the United States using NHANES data, a meta-analysis of observational studies of systolic blood pressure, and a meta-analysis of systolic blood pressure treatment trials. The study by Millett et al uses survey and electronic medical record data from family practices in the United Kingdom to examine the impact of a systems-level intervention (pay for performance) on reducing racial and ethnic disparities in the management of hypertension. Both studies highlight the fact that persons of African descent (Caribbean and African blacks and African Americans) have a higher prevalence of hypertension than persons of European descent (whites) and therefore may be at increased risk of cardiovascular disease. Both studies compare rates of hypertension control for blacks and whites; the Millett et al study also provides comparison data for South Asians.

Fiscella and Holt found that a reduction in mean systolic blood pressure among blacks to that of whites would reduce the annual number of black deaths from heart disease by 5,590 and from stroke by 2,190.

This study contributes greatly to the literature on the impact of racial disparities on cardiovascular mortality and highlights the substantial public health impact that reducing disparities in hypertension control in 
the United States could have. As the authors acknowledge, however, the best strategy for eliminating racial and ethnic disparities in hypertension control remains elusive. They argue that in the absence of evidence for disparities in hypertension treatment or severity, efforts should focus on addressing patients' adherence barriers

Millet et $\mathrm{al}^{12}$ found that whereas no ethnic disparities existed in blood pressure measurement, disparities in medication prescribing and in the achievement of blood pressure control persisted despite a major investment in quality improvement initiatives, including pay for performance. These disparities in control were particularly marked in patients with multiple cardiovascular comorbidities, who arguably may be the sickest patients.

What can we learn from these studies on racial and ethnic disparities and systems-level interventions to reduce disparities? First, it seems clear that racial and ethnic disparities in hypertension control are pervasive and persistent regardless of whether access to health care is provided. In the United Kingdom, which has universal access to health care, thus eliminating major financial barriers to care for ethnic populations, disparities in care and outcomes persist. Furthermore, these disparities persist despite a sustained period of investment by the United Kingdom in improving health care quality. In the United States, the Veterans Affairs (VA) health system is the closest surrogate to a universal access environment. In studies conducted in the VA system, where access barriers are fewer (including access to affordable medications), racial disparities in hypertension control are reduced but still not eliminated. ${ }^{13}$ It appears, therefore, that while improving access to health care is an important and necessary step, efforts to eliminate racial and ethnic disparities must extend beyond simply improving access.

Second, given that overcoming traditional access barriers, such as health insurance and primary care, does not eliminate disparities in health outcomes, we must seek to understand and address factors that initiate and sustain disparities among those who are in care, as well as the more upstream or fundamental causes of disparities. Doing so will include a closer examination of differences within ethnic groups that contribute to blood pressure control. Such an approach may allow us to better understand the variability in health practices within ethnic groups. We submit that greater effort should be directed at understanding positive deviance as it relates to racial and ethnic disparities in cardiovascular outcomes. Positive deviance is the observation that in most settings a few at-risk individuals follow uncommon, beneficial practices and consequently experience better outcomes than their neighbors who share similar risks. ${ }^{14}$ Positive deviance approaches can be applied for use with existing data sets as a tool for understanding and reducing health disparities. ${ }^{15}$ This framework shift in our thinking about disparities may prove valuable as we design interventions to improve disease outcomes.

Third, there is some evidence that patient adherence contributes to disparities in control of high blood pressure. The authors of both articles highlight the issue of adherence and acknowledge that their studies did not account for variations in adherence to medications - a factor that undoubtedly affects blood pressure control and is known to differ by race and ethnicity. Understanding how racial and ethnic disparities in adherence contribute to suboptimal hypertension control is critical for developing and evaluating interventions. Patient adherence to health-supporting behaviors (eg, taking their medications as directed, exercising, eating a healthy diet, avoiding smoking and illicit substance use) and clinician adherence (eg, following evidence-based guidelines, intensifying antihypertensive medications as appropriate) are both important for optimal blood pressure control. In addition to the typical barriers to adherence, for ethnic minorities it is important to consider the roles of disparate beliefs about health and illness, acceptability of various treatments, issues of trust in health care clinicians, and previous experiences of unfair or discriminatory treatment in health care. ${ }^{16}$

Even so, focusing solely on individual-level characteristics of either patients or clinicians may not be sufficient to truly understand the multiple determinants of a phenomenon as complex as adherence. We need to also examine how aspects of the broader social environment (eg, neighborhood or community characteristics, social networks, and social support) contribute to racial and ethnic disparities in health behaviors and outcomes through the use of multilevel modeling, social network analyses, and studies that use mixed qualitative and quantitative methods. Ultimately, interventions to improve adherence, reduce disparities, and improve blood pressure control should be targeted at multiple levels (eg, individual patient, patient-clinician interaction, health care system, and the social environment).

Finally, fundamental questions remain regarding the effectiveness of quality improvement initiatives for reducing or eliminating racial and ethnic disparities in health care and outcomes. Although in theory generic quality improvement initiatives should improve care and outcomes for all, it is unclear whether those at greatest risk, such as ethnic minorities, will benefit the most. Strategies to reduce disparities have targeted individual patient factors, ${ }^{17-19}$ clinician factors, ${ }^{20,21}$ health systems factors, ${ }^{19,22-24}$ or a combination of these. ${ }^{25-27}$ Addition- 
ally, performance incentive programs, such as pay for performance and public reporting systems, have been instituted to improve health care quality and to reduce racial and ethnic disparities in care. ${ }^{28,29}$

Systematic reviews and other studies that examine the impact of quality improvement strategies on various processes of care and health outcomes, including their impact on disparity reduction, have inconclusive results. ${ }^{24,28,30}$ Some studies show that ethnic disparities in processes of care can be reduced or eliminated. ${ }^{31,32}$ Others show that generic quality improvement programs reduce ethnic disparities in some processes of care, but not necessarily health outcomes. ${ }^{30,33,34}$ At least 1 empirical study shows that a major public reporting program actually increases disparities. ${ }^{28}$ Few studies specifically examine strategies to improve the quality of health care for minorities, and even fewer examine the reduction of racial disparities as an outcome. ${ }^{35}$ A systematic review of the effect of culturally tailoring interventions on disparities found that most interventions did not actually assess health outcomes, and when they did, the effect was marginal. ${ }^{19}$ In summary, although the evidence is growing, the particular characteristics that make quality improvement programs successful at reducing disparities, their impact on health outcomes and their sustainability over time are largely unknown. The definitive answer to the question of whether quality improvement initiatives for reducing or eliminating racial and ethnic disparities in health care and outcomes lies in the design of the programs and the rigor of the evaluation methods.

Together, the articles by Fiscella and Holt and Millet and colleagues in this issue of the Annals of Family Medicine are valuable additions to the literature on ethnic disparities in health care. They serve as an urgent call for clinicians, researchers, health care administrators, social activists, and policy makers in the United States and the United Kingdom to work together to gain a better understanding about how critical barriers experienced by ethnic minorities within and outside the health care system interact and to develop intensive and comprehensive strategies to overcome them. As we strive to eliminate disparities in care, we must realize that disparities in outcomes will persist until we address the social and political environments, within which health care exists, that perpetuate global health disparities.

To read or post commentaries in response to this article, see it online at http://www.annfammed.org/cgi/content/full/6/6/486.

Key words: Cardiovascular diseases; health care disparities; accessibility of health services; medically underserved area

Submitted September 26, 2008; accepted September 26, 2008.
Funding support: Dr Cooper is supported by a grant from the National Heart, Lung, and Blood Institute (K24HL083113).

\section{References}

1. World Health Organization. Cardiovascular diseases [ Web page]. 2007. http://www.who.int/mediacentre/factsheets/fs317/en/index. html.

2. Mendis S, Lindholm LH, Mancia G, et al. World health organization (WHO) and international society of hypertension (ISH) risk prediction charts: assessment of cardiovascular risk for prevention and control of cardiovascular disease in low and middle-income countries. J Hypertens. 2007;25(8):1578-1582.

3. Lawes CM, Vander Hoorn S, Law MR, Elliott P, MacMahon S, Rodgers A. Blood pressure and the global burden of disease 2000. part II: estimates of attributable burden. J Hypertens. 2006;24(3): 423-430.

4. Smedley BD, Stith AY, Nelson AR, for the Committee on Understanding and Eliminating Rational and Ethnic Disparities in Health Care, ed. Unequal Treatment: Confronting Racial and Ethnic Disparities in Health Care. Washington, DC: National Academies of Science; 2003.

5. Barnett $E$, Halverson J. Local increases in coronary heart disease mortality among blacks and whites in the United States, 1985-1995. Am J Public Health. 2001;91(9):1499-1506.

6. Hertz RP, Unger AN, Cornell JA, Saunders E. Racial disparities in hypertension prevalence, awareness, and management. Arch Intern Med. 2005;165(18):2098-2104.

7. Lillie-Blanton M, Maddox TM, Rushing O, Mensah GA. Disparities in cardiac care: rising to the challenge of healthy people 2010. J Am Coll Cardiol. 2004;44(3):503-508.

8. Wong MD, Shapiro MF, Boscardin WJ, Ettner SL. Contribution of major diseases to disparities in mortality. $N$ Engl J Med. 2002;347(20):1585-1592.

9. Chaturvedi N, McKeigue PM, Marmot MG. Resting and ambulatory blood pressure differences in Afro-Caribbeans and Europeans. Hypertension. 1993;22(1):90-96.

10. Khattar RS, Swales JD, Senior R, Lahiri A. Racial variation in cardiovascular morbidity and mortality in essential hypertension. Heart. 2000;83(3):267-271.

11. Fiscella K, Holt K. Racial disparity in hypertension control: tallying the death toll. Ann Fam Med. 2008;6(6):497-502.

12. Millett C, Gray J, Bottle A, Majeed A. Ethnic disparities in blood pressure management in patients with hypertension after the introduction of pay for performance. Ann Fam Med. 2008;6(6):490-496.

13. Rehman SU, Hutchison FN, Hendrix K, Okonofua EC, Egan BM. Ethnic differences in blood pressure control among men at veterans affairs clinics and other health care sites. Arch Intern Med. 2005;165(9):1041-1047.

14. Berggren WL, Wray JD. Positive deviant behavior and nutrition education. Food Nutr Bull. 2002;23(4)(Suppl):9-10.

15. Walker LO, Sterling BS, Hoke MM, Dearden KA. Applying the concept of positive deviance to public health data: A tool for reducing health disparities. Public Health Nurs. 2007;24(6):571-576.

16. Cooper LA, Hill MN, Powe NR. Designing and evaluating interventions to eliminate racial and ethnic disparities in health care. J Gen Intern Med. 2002;17(6):477-486.

17. Bosworth HB, Olsen MK, Neary A, et al. Take control of your blood pressure (TCYB) study: A multifactorial tailored behavioral and educational intervention for achieving blood pressure control. Patient Educ Couns. 2008;70(3):338-347.

18. Boulware LE, Daumit GL, Frick KD, Minkovitz CS, Lawrence RS, Powe NR. An evidence-based review of patient-centered behavioral interventions for hypertension. Am J Prev Med. 2001;21(3):221-232. 
19. Fisher TL, Burnet DL, Huang ES, Chin MH, Cagney KA. Cultural leverage: interventions using culture to narrow racial disparities in health care. Med Care Res Rev. 2007;64(5)(Suppl):243S-282S.

20. Beach MC, Gary TL, Price EG, et al. Improving health care quality for racial/ethnic minorities: A systematic review of the best evidence regarding provider and organization interventions. BMC Public Health. 2006;6:104.

21. Beach MC, Price EG, Gary TL, et al. Cultural competence: A systematic review of health care provider educational interventions. Med Care. 2005;43(4):356-373.

22. Becker DM, Yanek LR, Johnson WR Jr, et al. Impact of a community-based multiple risk factor intervention on cardiovascular risk in black families with a history of premature coronary disease. Circulation. 2005;111(10):1298-1304.

23. Brownstein JN, Chowdhury FM, Norris SL, et al. Effectiveness of community health workers in the care of people with hypertension. Am J Prev Med. 2007;32(5):435-447.

24. Peek ME, Cargill A, Huang ES. Diabetes health disparities: A systematic review of health care interventions. Med Care Res Rev. 2007;64(5)(Suppl):101S-156S.

25. ClinicalTrials.gov. Patient-physician partnership to improve high blood pressure adherence [Web page]. 2008. http://clinicaltrials. gov/ct2/show/NCT00123045?term = Patient-Physician + Partnership\& rank=1.

26. Roumie CL, Elasy TA, Greevy R, et al. Improving blood pressure control through provider education, provider alerts, and patient education: A cluster randomized trial. Ann Intern Med. 2006;145(3):165-175.
27. Davis AM, Vinci LM, Okwuosa TM, Chase AR, Huang ES. Cardiovas cular health disparities: A systematic review of health care interventions. Med Care Res Rev. 2007;64(5)(Suppl):29S-100S.

28. Chien AT, Chin MH, Davis AM, Casalino LP. Pay for performance, public reporting, and racial disparities in health care: How are programs being designed? Med Care Res Rev. 2007;64(5)(Suppl): 2835-3045.

29. Petersen LA, Woodard LD, Urech T, Daw C, Sookanan S. Does pay-for-performance improve the quality of health care? Ann Intern Med. 2006;145(4):265-272.

30. Sequist TD, Adams A, Zhang F, Ross-Degnan D, Ayanian JZ. Effect of quality improvement on racial disparities in diabetes care. Arch Intern Med. 2006;166(6):675-681.

31. Asch SM, Kerr EA, Keesey J, et al. Who is at greatest risk for receiving poor-quality health care? N Engl J Med. 2006;354(11):1147-1156.

32. Ma J, Stafford RS. Quality of US outpatient care: Temporal changes and racial/ethnic disparities. Arch Intern Med. 2005;165(12):1354-1361.

33. Trivedi AN, Zaslavsky AM, Schneider EC, Ayanian JZ. Trends in the quality of care and racial disparities in medicare managed care. $N$ Engl J Med. 2005;353(7):692-700.

34. Sehgal AR. Impact of quality improvement efforts on race and sex disparities in hemodialysis. JAMA. 2003;289(8):996-1000.

35. Chin MH, Walters AE, Cook SC, Huang ES. Interventions to reduce racial and ethnic disparities in health care. Med Care Res Rev. 2007;64(5)(Suppl):7S-28S. 